DOI: 10.20472/IAC.2019.050.016

\author{
SHAIMAA HELAL \\ Arab Open University, Saudi Arabia
}

\title{
GRAMMATICAL FEATURES AND THEIR RELATIONS TO THE REVELATION OF MEANING IN HAWTHORNE'S THE SCARLET LETTER WITH SPECIAL FOCUS ON THE PURITANS' NARRATIVE SENTENCES
}

\begin{abstract}
:
The linguistic studies specifically the grammatical studies of Hawthorne's The Scarlet letter are almost lacking, although of the richness of Hawthorne's language employed in the revelation of all characters: Hester Prynne, Arthur Dimmesdale, Roger Chillingworth and Pearl. From this point, emerges the importance of the current study that sheds much light on the relationship between the diverse syntactic structures selected by Hawthorne in dealing with Puritans and their beliefs in order to create certain effect on the reader, and the revelation of the meaning as a whole. Obviously, in The Scarlet Letter, the Puritan themes of the universality of sin bothered Hawthorne's mind (Peleng et al.2018; Mahini 2018; among others). The aim of the study is to analyze the main stylistic features of Puritans' narrative sentences via various syntactic structures and to appreciate the array of the writer's syntactic choices that lead to specific structure and eventually interpretation of the text as well as revelation of the meaning. The focus will be on the writer use of various grammatical features as effective stylistic features in Puritans' narrative sentences. The parsing of the narrative sentences that are related to the Puritans follows the syntactic system used in Leech et al (1982). This system is chosen to represent the syntactic analysis related to framework of the paper, because it provides not only a simplified method of syntactic analysis, but also a concise one. Breaking Puritans' narrative sentences into their syntactic components enables the researcher to analyze each component alone, on its own terms, and understand how it fits together with other syntactic components. Deep syntactic analysis increases the appreciation of the text as a whole (Thonborrow $\&$ Wareing, 1998). This paper reaches the conclusion that Hawthorne successfully employs different stylistic features, particularly the use of subordination (i.e. nesting) as well as the use of the process of retaining the most complex structure to the end of the sentence, to reveal various aspects of the Puritans such as their severity, and their psychological limitation of behavior. These features are embedding (nesting) $(62.85 \%)$, retaining the most complex structure to the end of the sentence $(48.780 \%)$, fronting an element ( whether subject, object, or complement) (43.902\%), distancing structurally related items (43.902\%), use of parenthetical constituent $(29.268 \%)$, use of periodic sentences $(17.073 \%)$, and other grammatical features that will be discussed in the paper.
\end{abstract}

\section{Keywords:}

Puritans, Sin, Syntactic constituents, Grammatical Analysis, Syntax and Meaning 